CAMHS or other psychological services, however, one-quarter (24\%) were discharged home without further follow-up, and $3 \%$ left before assessment.

Conclusion Over a ten-year period, rates of self-harm in all age groups (10-24) increased by $22 \%$, but the largest increase was in youth aged under $10-14 \quad(+82 \%)$. The increasing rates as well as increases in methods of self-harm associated with higher lethality underline the need for interventions to reduce risk of repeat self-harm and suicide among this population. Presentations to hospital provide an opportunity to provide appropriate referral and treatment options for those engaging in self-harm. Having access to child and adolescent psychiatry services in pediatric hospitals would allow appropriate consultation, but in the absence of such services, it is essential that pediatric staff are competent in providing a therapeutic assessment and aware of appropriate service to refer on to.

\section{GP157 QUALITY, TRUSTWORTHINESS, READABILITY, AND ACCURACY OF MEDICAL INFORMATION REGARDING COMMON PEDIATRIC EMERGENCY MEDICINE-RELATED COMPLAINTS ON THE WEB}

${ }^{1}$ Ava Rothrock* ${ }^{2}$ Valeria Chavez, ${ }^{3}$ Jake Romney, ${ }^{4}$ Shira Isaak, ${ }^{5}$ Maria Pagane ${ }^{1}$ Sarah Swetland, '6Steven Rothrock, ${ }^{6}$ Silvio Chavez. 'Oviedo High School, Oviedo, USA; ${ }^{2}$ Vanderbilt University, Nashville, USA; ${ }^{3}$ Lake Mary Preparatory School, Lake Mary, USA; ${ }^{4}$ Winter Park High School, Winter Park, USA; ${ }^{5}$ Columbia University, New York, USA; ${ }^{6}$ Orlando Health, Orlando, USA

\subsection{6/archdischild-2019-epa.221}

Study Objectives To analyze the adequacy of information on the internet directed at parents regarding common acute pediatric complaints.

Methods Authors searched three internet search engines for four common acute pediatric complaints (child + fever, vomiting, cough, abdomen pain) assessing the first 20 results for each query. Website readability was evaluated using a composite of the Flesch-Kincaid Grade Level, Gunning Fog Scale, Simple Measure of Gobbledygook Score and Coleman-Liau Index. Quality and trustworthiness were independently assessed by two reviewers using JAMA Benchmark Criteria and National Library of Medicine (NLM) Trustworthy scores. Accuracy was independently assessed by two board-certified physicians (emergency medicine, pediatric emergency medicine) who analyzed text with website and author identifiers deleted. Accuracy was calculated by dividing the number of correct by the total number of correct and incorrect medical statements. Disagreements regarding physician accuracy were settled by a third physician.

Accuracy was defined as $\geq 95 \%$ correct, readability as an $8^{\text {th }}$ grade or lower reading level, high quality as $\geq 3$ JAMA criteria, and trustworthiness as an NLM total score $\geq 3$ with all sub-scores $>0$.

Features of accurate and inaccurate websites were compared using chi-square analysis for categorical data, and Mann-Whitney $\mathrm{U}$ for continuous and ordinal data. Association between website accuracy and search rank order was measured using Spearman's correlation coefficient. Inter-rater reliability of website accuracy, JAMA criteria and NLM scores was measured using Cohen's kappa (k).

Results Ninety-six websites that were duplicates or directed at health professionals were excluded, leaving 144 evaluable websites. Of these, 60 (42\%) were readable, 49 (34\%) were certified as reliable by the Health on the Net (HON) Foundation, $38(26 \%)$ had high quality JAMA criteria $(\mathrm{k}=0.68)$, and $44(31 \%)$ had reliable NLM trustworthy scores $(\mathrm{k}=$ 0.66). Physicians graded 87 websites $(60 \%)$ as accurate $(\mathrm{k}=$ 0.94). Professional medical organizations (hospitals, academic societies, governments) more frequently published accurate websites compared to individuals and non-professional websites. $(74 \%$ vs. $46 \%, \mathrm{p}<0.01)$. There was no correlation between accuracy and search rank order (rho $=-0.05,-0.21$ to $0.12,95 \% \mathrm{CI})$. There was no association between accuracy and physician authorship, quality, trustworthiness, readability, article age or HON certification.

Conclusion Most studied websites had poor quality, readability, and trustworthiness. Many websites were also inaccurate. Because inadequate web-based information might adversely influence parents' medical decisions, measures should be taken to ensure information related to acute pediatric complaints is of high quality, readable, trustworthy, and accurate.

\section{GP158 THE USE OF NITROUS OXIDE IN TEMPLE STREET EMERGENCY DEPARTMENT}

Danielle McCollum*, Jim Hickson, Niamh Whyte, Patrick Fitzpatrick. Children's University Hospital, Temple Street, Dublin, Ireland

\subsection{6/archdischild-2019-epa.222}

Background A visit to the Emergency Department (ED) can be stressful and frightening for children and their parents. ${ }^{1}$ Children perceive many of the interventions performed in ED as threatening, and a negative experience can have an impact on any future visits to hospital. ${ }^{2 ;} 3$ Through our procedural sedation programme, we aim to minimise this distress, reduce pain and improve the success rate of a procedure whilst ensuring patient safety at all times.

Aims The aim of this study is to review the use of Nitrous Oxide for procedural sedation within the Emergency Department between March and October 2018, and to evaluate the adverse events and outcomes.

Methods When performing procedural sedation in ED, a standardised sedation record is completed by the trained staff member and uploaded to a computer database. These forms were reviewed and data was input into Microsoft Excel for interpretation and analysis.

Results Over the study period, procedural sedation was performed on 142 occasions. The mean age of the patients was 6.9 years old (11 months - 15 year), and 68\% were male. The overall mean duration of sedation was 9.3 minutes (3minutes - 40minutes). The most common indication for use of Nitrous Oxide was in the management of a fracture or laceration (93/142). Other indications included removal of foreign bodies, lumbar punctures and IV cannulation. No serious adverse events occurred in the study period. Less significant side effects occurred in $22 \%$ of cases. Vomiting was the most common (27/142) side effect and was more likely to occur in children under 10 years of age.

Conclusion Nitrous oxide is used for a wide variety of reasons in our department and is generally well tolerated. Procedural sedation can be beneficial to patients in reducing distress and avoiding a general anaesthetic with prolonged hospital stays. The implantation of a database allows for continuous audit of our practices within the department and comparison with national and international standards. 


\section{REFERENCES}

1. Merritt C. Fear and loathing in the ER: managing procedural pain and anxiety in the Pediatric Emergency Department. $R$ / Med J 2013; 97(1):31-34.

2. Krauss B. S.; GREEN, S. M. Procedural sedation and its place in paediatric emergency medicine. Emergency Medicine Journal; 33(8):525.

3. Krieser D, Kochar A. Paediatric procedural sedation within the emergency department. J Paediatr Child Health 2016; 52(2):197-203.

\section{GP159 CHILDREN BROUGHT TO THE EMERGENCY DEPARTMENT UNDER SECTION 12: A TEN-YEAR REVIEW}

${ }^{1}$ MO'Riordan Aisling*, ${ }^{2}$ Niamh Swannick Byrne, ${ }^{1}$ Abrar Haider, ${ }^{1}$ Husnain Mahomed, ${ }^{1}$ Peter O'Reilly, ${ }^{1}$ Siobhan Gallagher, ${ }^{1}$ Anne-Marie Murphy. ${ }^{1}$ University Hospital Limerick, Limerick, Ireland; ${ }^{2}$ University of Limerick Department of Paediatrics, Limerick, Ireland

10.1136/archdischild-2019-epa.223

Background Under Section 12 of the Child Care Act (1991) a child may be removed from the care of their family where a member of an Garda Síochána believes 'there is an immediate and serious risk to the health or welfare of a child'. In these circumstances where a foster placement is not readily available the hospital may become a de facto place of safety to which children are brought.

Aim We carried out a retrospective review of all children, under the age of 18, attending the Emergency Department (ED) at University Hospital Limerick (UHL) over a 10-year period, from January 2008 to December 2017, to evaluate the demand placed on the service and to look at any changes in the demographics of this population.

Results There were 174 cases where a child was brought to the ED, under a Section 12, in this period. This included a total of 165 children, from 135 families. There was approximately an even distribution of ages, $<1$ year 20\%, 1-5 years $24 \%, 5-12$ years 22\%, $12-16$ years $26 \%$ and $>16$ years $8 \%$. There was no significant pattern of change in age distribution over time (figure 1).

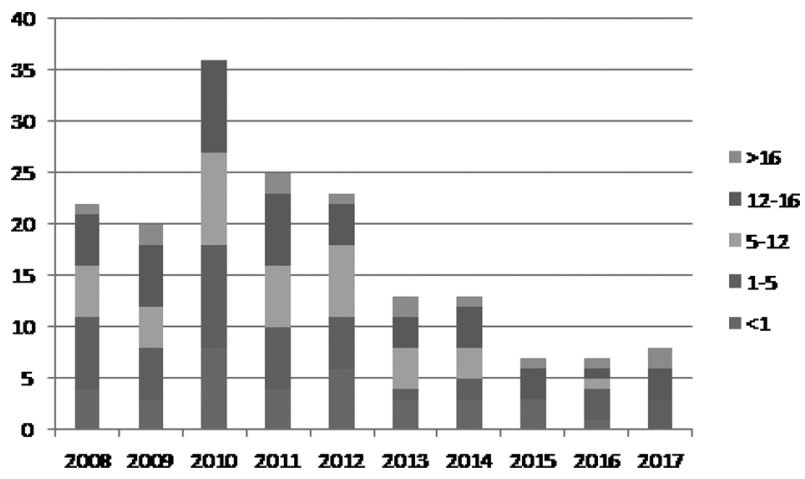

Abstract GP159 Figure 1 Graph of annual number with age distribution per year

Conclusion This report shows that there is a significant burden placed on the ED by children brought under Section 12 for a place of safety. In most cases the children were in good health and the hospital was not an appropriate environment for them. in this study there were higher numbers of children requiring a place of safety during the economic recession. The fall in numbers may reflect the recent improvement in the economy. A prospective study is planned to look at all section $12 \mathrm{~s}$ in our department with a view to appropriate planning of services and provision of care.

\section{GP161 COST ANALYSIS OF ACUTE MENTAL HEALTH PRESENTATIONS TO PEDIATRIC EMERGENCY DEPARTMENTS IN 2016-2018}

${ }^{1}$ Ruairi McNicholas*, 2,1 Fionn Lynch, ${ }^{3,1}$ Kristen Mauder, ${ }^{1,4}$ Rachael Quirke, 1,4,5Fiona McNicholas. ' UCD, Dublin, Ireland; ${ }^{2}$ St Vincents Hosp, Dublin, Ireland; ${ }^{3}$ St Patricks University Hospital, Dublin, Ireland; ${ }^{4}$ OLCHC Crumlin, Dublin, Ireland; ${ }^{5}$ Lucena Clinic SJOG, Dublin, Ireland

\subsection{6/archdischild-2019-epa.224}

Inadequate out of hours CAMHS has meant youth with mental health $(\mathrm{MH})$ crisis increasingly present to Emergency Departments of pediatric hospitals. Many are admitted to allow for a $\mathrm{MH}$ assessment the next working day. Lack of access to a specialist $\mathrm{MH}$ in-patient beds also means that those identified with serious mental illness may have to remain in a pediatric hospital bed for many days until an appropriate bed becomes available. This may place the young person, other patients and staff at risk, as most pediatric hospitals do not have appropriately trained staff to carry out this function, and most have not been architecturally designed to ensure they meet the required safety standards applied to $\mathrm{MH}$ units. Furthermore, frequent and prolonged admissions have cost implications to the hospital, and have often not been included in year on year panning.

This study looks at the cost implications for youth presenting to a pediatric hospital and examines trends over time.

All emergency $\mathrm{MH}$ admissions were identified over a 6 month period (Jan-June) in 2018. Costs associated with length of stay (LOS) were calculated and compared with data in 2016. Pattern of presentation over time and presentation type was examined.

In 2018, 87 cases presented to the Emergency Department, 59 were female $(68 \%)$ with a mean age of $13(6-15) .42$ $(48 \%)$ arrived outside of normal working hours, and the majority $(66,76 \%)$ were admitted. The typical presentation was with either Suicidal ideation, present in 58 (67\%) or active deliberate self harm $(45,52 \%)$. The average LOS was 8.7 days, with a mode of 5 (range $0-74$ ) amounting to a total of 574 bed days.

In the 12 months of 2016, there were 105 admissions following acute $\mathrm{MH}$ presentation, with an average LOS of 6 days, a total of 615 bed days, giving a year long cost of $€ 1,216,470$, an average cost/patient of $€ 12,684$. Using the same cost price $(€ 1,978$ inclusive of pay and non-pay expenses), rates for the first 6 months of 2018 already exceed 2016 full year figures, with $€ 1,135,372$ or $€ 17,203$ per youth admitted.

Despite an increasing number of dedicated $\mathrm{MH}$ beds, demand outweighs availability, and immediate access is problematic, the default often being a pediatric admission. Appropriate use and adequate funding of these scare and costly resources must be part of national $\mathrm{MH}$ policy planning, especially with ongoing planning for the National Children's' Hospital. 